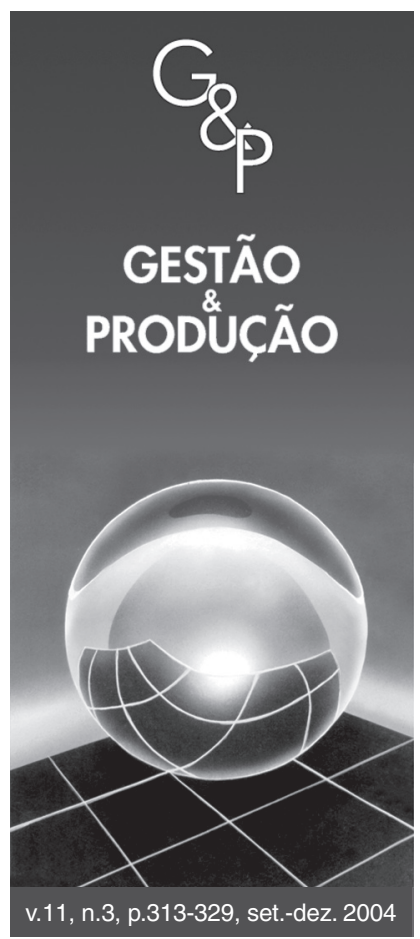

\title{
ANÁLISE DE POLÍTICAS DE GESTÃO EM CADEIAS DE SUPRIMENTOS POR MODELOS DE SIMULAÇÃO
}

\author{
Carlos Machado de Oliveira \\ Faculdade de Engenharia Mecânica, \\ Universidade Estadual de Campinas, \\ Rua Mendeleiev, s/n, Cidade Universitária, Campinas, SP, \\ e-mail: cmachado_br@yahoo.com \\ Marcius Fabius Henriques de Carvalho \\ Centro de Pesquisas Renato Archer, CenPRA, \\ C.P. 6162 , Campinas, SP, \\ e-mail: marcius.carvalho@ cenpra.gov.br
}

Resumo

A comparação de diferentes enfoques para a distribuição da informação e gestão é relevante para o projeto e a operação de Cadeias de Suprimentos. Por ela, ganhos no nível de serviço podem ser identificados, seja por maior troca de informação ou por aumento de estoque, e seus custos, medidos. Este artigo discute os enfoques distribuído e centralizado para a gestão, define um ambiente para Simulação distribuída entre empresas, projetado especificamente para a representação de Cadeias de Suprimentos, que tem como principal vantagem a evolução em tempo discreto da simulação e, por fim, utiliza uma aplicação para demonstrar os recursos do ambiente e avaliar os ganhos obtidos, quando aplicadas diferentes políticas de distribuição da informação e gestão.

Palavras-chave: cadeias de suprimentos, simulação distribuída, políticas de gestão, empresa cooperativa, gestão de empresas.

\section{Introdução}

Uma empresa, inserida em um mercado globalizado, busca vantagem competitiva pela desintegração vertical, terceirização e foco nas atividades essenciais. Após a desverticalização, aparece a necessidade de formação de alianças estratégicas entre empresas baseadas no interesse de mercado em comum e, assim, surge o conceito de Cadeia de Suprimentos (CS), definido como uma rede de entidades de negócio, parcialmente ou totalmente autônomas, coletivamente responsáveis por atividades de suprimentos, manufatura, distribuição e marketing de produtos (Stevens, 1989).

Esta configuração de produção, que envolve compartilhamento de processos entre empresas, deve ser gerenciada no sentido de integrar eficientemente fornecedores, fabricantes, distribuidores, tal que os bens sejam produzidos e distribuídos nas quantidades certas, nos locais certos e na hora certa, satisfazendo as expectativas dos clientes a custo mínimo (Simchi-Levi et al. 2000).

Para tanto, a integração, que pode apresentar-se em diferentes formas, fundamentada na cooperação entre empresas parceiras, torna-se essencial. A cooperação considera que as empresas parceiras trabalham de forma independente, contudo com objetivos e estratégias comuns. De acordo com a estratégia de cooperação, a gestão pode ser classificada em duas formas: a gestão centralizada e a gestão descentralizada, (Lee e Billington, 1993; Simchi-Levi et al., 2000; Azevedo e Souza, 2000).

A gestão centralizada, utilizada principalmente quando a rede pertence a uma única empresa ou possui um participante dominante, é composta de um nível de coordenação e de um nível de empresas (Carvalho e Campos, 1997). No nível de coordenação, as decisões de quando, onde e quem produzir são tomadas centralmente, pela empresa coordenadora da cadeia, baseadas nos requisitos de demanda e no status de todo o sistema produtivo. O objetivo é atender a determinado segmento 
de mercado, segundo nível de serviço especificado, de forma a otimizar os custos de produção, armazenagem e transporte. Como exemplo aparecem as empresas montadoras, na indústria automotiva e de computadores. Já, na indústria de confecções, são as empresas que detêm a distribuição e Marca do produto.

A descentralização da decisão é um caminho inevitável para a gestão de grandes organizações, que, constantemente, se deparam com a tomada de decisão em intervalos cada vez mais curtos. Um meio efetivo de atingir tal desafio em um ambiente multi-empresas é a delegação da decisão a cada empresa, porém considerando o impacto desta em seus parceiros de negócio. Segundo Oliver et al. (2001), a solução para maior eficiência, em uma Cadeia de Suprimentos descentralizada, não reside em tecnologia "sem atrito", mas no compartilhamento de objetivos e percepções ao longo da empresa estendida e no reconhecimento de cada parceiro como um "cidadão" independente, dentro de múltiplas redes. Um problema na descentralização é que ela não garante uma solução ótima para a CS, mas pode buscar uma solução de consenso entre empresas, quando adotadas regras corporativas, baseadas em medidas de desempenho e restrições operacionais (Lee e Whang, 1999).

Ambos os enfoques de gestão, que podem ser encontrados, simultaneamente, em uma mesma empresa, são complexos e apresentam objetivos conflitantes. Para análise de diferentes cenários e configurações de produção, na busca de uma solução adequada, torna-se necessário o apoio de ferramentas. Enfoques analíticos, especialmente a representação por programação linear, são aplicados a problemas de produção, com múltiplos parceiros, em múltiplos períodos, (Furtado e Carvalho, 2002). Tornamse mais rápidos, quando os algoritmos de solução aproveitam a estrutura particular do problema pela representação da coordenação no tempo do fluxo entre parceiros, por um modelo de fluxo em redes. Contudo, a programação linear apresenta dificuldades em considerar as regras de negócio e os efeitos aleatórios associados ao sistema de produção, transporte, fornecedores e demanda.

No nível de planejamento operacional, a ferramenta mais adequada é a simulação (Lee e Billington, 1993; Towill et al., 1992; Vernadat, 1999). Ela atua como uma ferramenta preditiva e ajuda na quantificação dos benefícios de políticas e regras de produção em ambientes com incerteza. Mas apresenta a desvantagem de consumir grande tempo computacional para sistemas de grande porte e de necessitar o acompanhamento de especialista em um ambiente de simulação, por vezes, não geral o suficiente para a representação adequada do problema.

Para que a simulação tenha maior aplicação, há esforços para integrar alguns tipos de modelos funcionais e de informação aos modelos de simulação (Srinivasan e
Jayaraman, 1999; Kellert et al., 1997; Weston e Gilders, 1996). Entretanto, eles empregam métodos orientados a entidade ou atividade como o Structured Analysis and Design Technique (SADT) (Marca e McGowan, 1988), que não são suficientes para projetar integração de empresa e entre empresas. Aparecem, também, esforços em tradutores de modelos SADT para modelos de simulação, contudo as estruturas dos modelos de empresa diferem em muito dos modelos de simulação utilizados, tornando a tradução um processo praticamente impossível (Vernadat, 1999).

Este artigo apresenta um ambiente para a simulação de Cadeias de Suprimentos e o utiliza para analisar os enfoques para compartilhamento da informação e formas de gestão. O algoritmo foi projetado, especificamente, para a representação de Cadeias de Suprimentos e apresenta como principal característica a evolução da simulação em intervalo discreto de tempo. A próxima seção apresenta os enfoques distribuído e centralizado para a gestão da cadeia, logo a seguir são feitas as considerações sobre a relação de negócio na cadeia e a troca de informação, que é utilizada para a decisão em tempo discreto. Na seção 4, é apresentado o ambiente para simulação de Cadeias de Suprimentos por modelos a tempos discretos. Por fim, uma aplicação evidencia as vantagens da proposta deste artigo para a análise da dinâmica da cadeia e de suas diferentes formas de gestão.

\section{Enfoques para a gestão da cadeia de suprimentos}

A melhoria de desempenho de uma CS pode vir pela redefinição do processo físico ou do processo de decisão. $\mathrm{O}$ último tem como elemento principal o compartilhamento da informação e, segundo Lee e Whang (2001), este é o caminho para a redução de custos, aumento de flexibilidade e obtenção de respostas mais rápidas e efetivas. Diferentes níveis de compartilhamento da informação resultam em diferentes formas de gestão, como apresentado na Figura 1. A Figura 1a considera que somente o varejista tenha acesso à informação da demanda do consumidor. Na Figura 1b, a informação da demanda do consumidor é distribuída para todos os elementos parceiros. Já na Figura 1c, cada empresa recebe informações de todos os componentes do sistema, havendo, portanto, um alto grau de compartilhamento da informação.

Pelo enfoque tradicional de troca de informação, Figura 1a, a gestão da produção é realizada da seguinte forma: cada empresa estabelece sua política de produção baseada na informação da demanda de seu cliente (Lee et al., 1997). Assim, a informação da demanda passa de empresa a empresa até atingir o fornecedor de matériaprima. Neste processo de transferência de informação, 


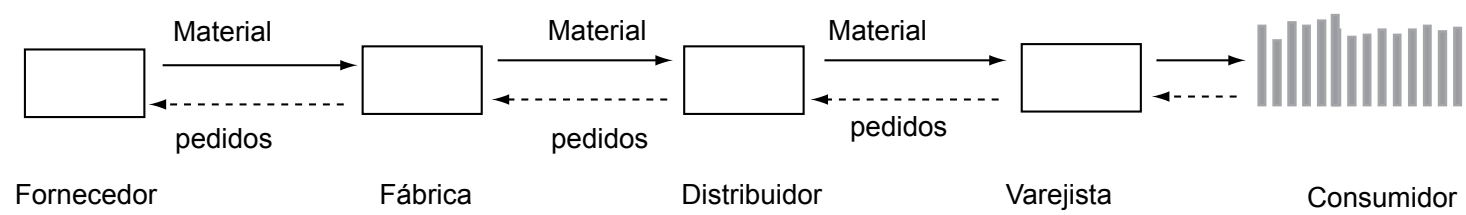

a) Troca de informação tradicional

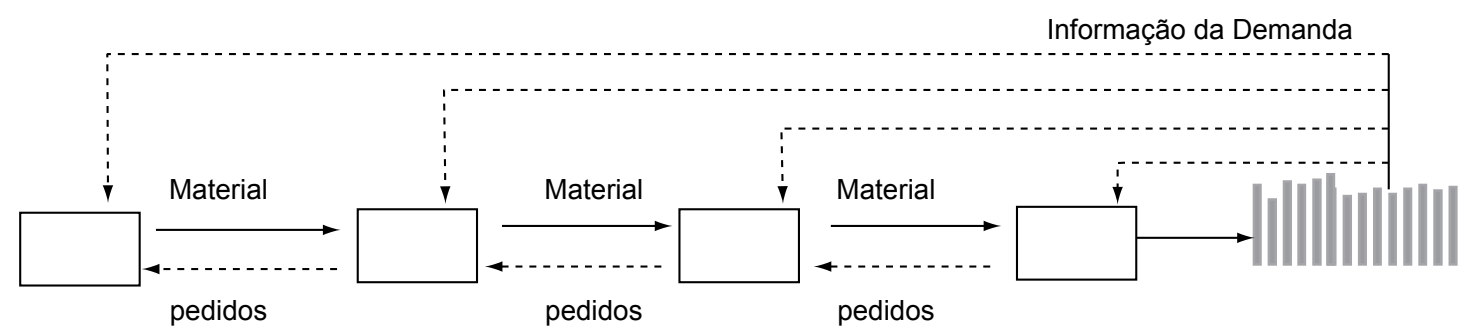

Fornecedor

Fábrica

Distribuidor

Varejista

Consumidor

b) Compartilhamento total da informação sobre a demanda

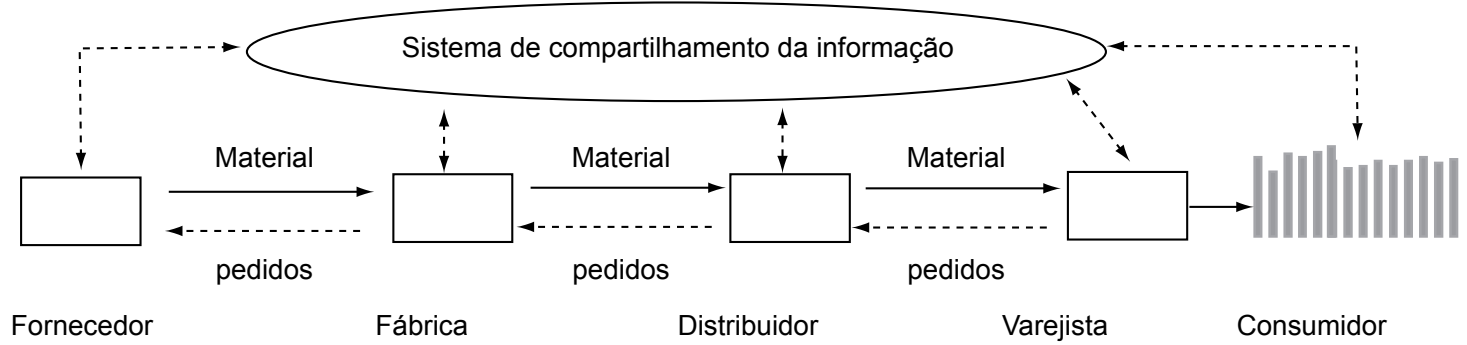

c) Compartilhamento total de informação

Figura 1. Formas de compartilhamento de informação.

pequenas variações na demanda do consumidor final levam a grandes variações nas colocações de pedidos às empresas situadas a montante da cadeia. Esta variação, que pode ser suavizada pelo aumento do nível de estoque, com conseqüente aumento do custo operacional (Towill et al. 1992), é conhecida como efeito chicote e contribui para a diminuição da competitividade do produto final, por conseguinte, competitividade da cadeia (Forrester, 1961).

$\mathrm{Na}$ forma de troca de informação proposta pela Figura 1b, compartilhamento estendido da demanda, a demanda do consumidor é distribuída para todos os membros da cadeia e cada parceiro usa esta informação e a informação da demanda de seu cliente imediato, para implementar sua política de produção e pedidos. Na Figura 1c, compartilhamento completo da informação, as informações das empresas são distribuídas entre os membros da cadeia. Para estabelecer sua produção e seus pedidos, cada empresa, baseada em suas regras internas, processa as informações de clientes e fornecedores. A proposta deste planejamento cooperativo descentralizado, uma vez que as decisões são internas a cada empresa, também conhecido como planejamento federativo, se baseia em três aspectos (Oliver et. al, 2001). A coordenação ocorre pela negociação entre empresas na busca do alinhamento dos objetivos do negócio, que estabeleça tendências e padrões ao longo do tempo no lugar de soluções pontuais. Os parceiros podem negociar nível de serviço, leadtime de reposição, preços, contrato de suprimento, lotes mínimos, com quem e com que frequiência compartilhar informações.

Uma das vantagens do planejamento federativo é sua capacidade de adaptar-se a diferentes estruturas e modelos de governança. O termo governança é utilizado para expressar as relações de negócio entre empresas. Como exemplo, uma empresa da cadeia estabelece parâmetros sob os quais outras empresas devem operar.

Uma forma para a determinação dos parâmetros é pelo estabelecimento de um planejamento que venha atingir níveis de serviços negociados entre todas as empresas. Este planejamento, realizado de modo "federativo", deve permitir que o fluxo de informação e decisão contenham regras operacionais que representem os acordos estabelecidos entre os parceiros. Por exemplo, permite especi- 
ficar o nível de serviço que um fornecedor deve seguir, determinado por acordo previamente estabelecido.

Nestes três esquemas, que apresentam níveis distintos de cooperação pela distribuição da informação, a decisão de produção e armazenagem ocorre dentro de cada empresa, baseada em informações dos parceiros sobre demandas, nível de estoque e regras internas a empresa.

O sistema centralizado de decisão, Figura 2, adota uma hierarquia em dois níveis. O nível de coordenação das empresas, em que o parceiro, que exerce a governança, gerencia o processo de produção, estabelecendo a seus parceiros o quanto produzir em cada período de tempo e, se for o caso, o quanto armazenar, ou seja, estabelecendo metas a serem atingidas por cada empresa parceira. O consórcio modular, controlado pela montadora, para montagem automotiva é um exemplo desta forma de gestão.

A coordenação do fluxo de produção entre os parceiros, no sentido de evitar estoques desnecessários e produção desbalanceada é a função mais importante do Sistema de Decisão centralizada. Ela considera três aspectos: espaço das empresas parceiras e capacidade produtiva, que devem ser balanceados para encontrar uma demanda variável no tempo. Por este enfoque, há um segundo nível de planejamento, nível de empresa, em que cada empresa assume o objetivo de cumprir as metas estabelecidas pelo nível cooperativo. Exemplos de planejamento centralizado são encontrados nas plantas de montagem modulares da indústria automotiva (Fredrikssonn, 2002) e na indústria de componentes eletrônicos (Aenzen e Shumway, 2002). Outro campo de aplicação deste enfoque é em agrupamentos produtivos, clusters, em que o elemento gestor pode ser assumido por uma associação ou pelo poder público.

\section{Considerações sobre a troca de infor- mação}

Um modelo para representação de uma Cadeia de Suprimentos deve considerar o fluxo de material, o fluxo de informação, as restrições de capacidade e operacionais e o modelo de decisão estabelecido pelas regras de negócio entre os parceiros. Portanto, antes de determinar qual o modelo a ser empregado para análise de um sistema produtivo, é necessário entender como ocorrem as trocas de informação e material entre empresas e como estas são gerenciadas. Algumas considerações são:

- Vários eventos ocorrem em curto espaço de tempo em cada empresa de uma CS. Contudo, a maioria se completa, se cancela ou pode ser acomodada na variável de folga do sistema. Então, somente os efeitos finais, que causem mudanças significativas, devem ser considerados na modelagem do processo de negócio entre empresas;

- Pequenas mudanças são importantes dentro da empresa, dado que elas descrevem a habilidade da empresa atingir os objetivos da cadeia. Assim, pode torna-se adequada uma representação mais detalhada da empresa, por exemplo, pela adoção de um modelo a tempo contínuo e a eventos discretos; e

- Os tempos para fluxo de informação e produção aumentam quando o intervalo de planejamento de cada empresa é diferente. Nesta situação, o processo de planejamento não é síncrono na cadeia. Então, a primeira atividade de coordenação é unificar os intervalos. Isto significa estabelecer um intervalo de tempo discreto e fixo, que resulte em um sincronismo na troca de informação e planejamento das empresas parceiras.

Estabelecida a convenção acima, a troca de informação e material, que ocorre dentro de um intervalo de tempo no sistema real, pode ser representada em tempo discreto, Figura 3. Por exemplo, as produções do fornecedor F1 e fornecedor F2, durante o intervalo de tempo $\mathrm{T}=1$, são enviadas, ao final do tempo $\mathrm{T}=1$, à empresa $\mathrm{M}$ para serem montadas no intervalo $\mathrm{T}=2$ ou posterior (tomando o tempo de transporte igual a zero). Durante o $\mathrm{T}=1$, a empresa montadora planeja suas necessidades futuras, baseando-se nos pedidos de seus clientes (distribuidores) e informações internas e, ao final do tempo $\mathrm{T}=1$, envia pedidos às empresas fornecedoras F1 e F2, que irão executá-los no tempo T2. Ou seja, é considerado que a troca de informação e material, durante um dado intervalo de tempo de um sistema real, só produz efeito no intervalo seguinte.

Adotado este modelo, as decisões sobre os fluxos de

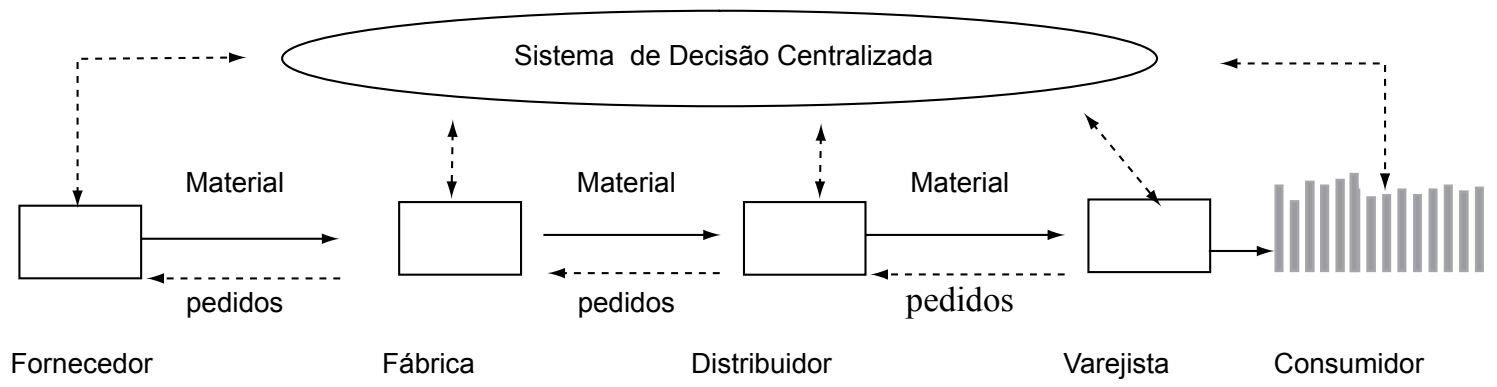

Figura 2. Sistema com decisão centralizada. 


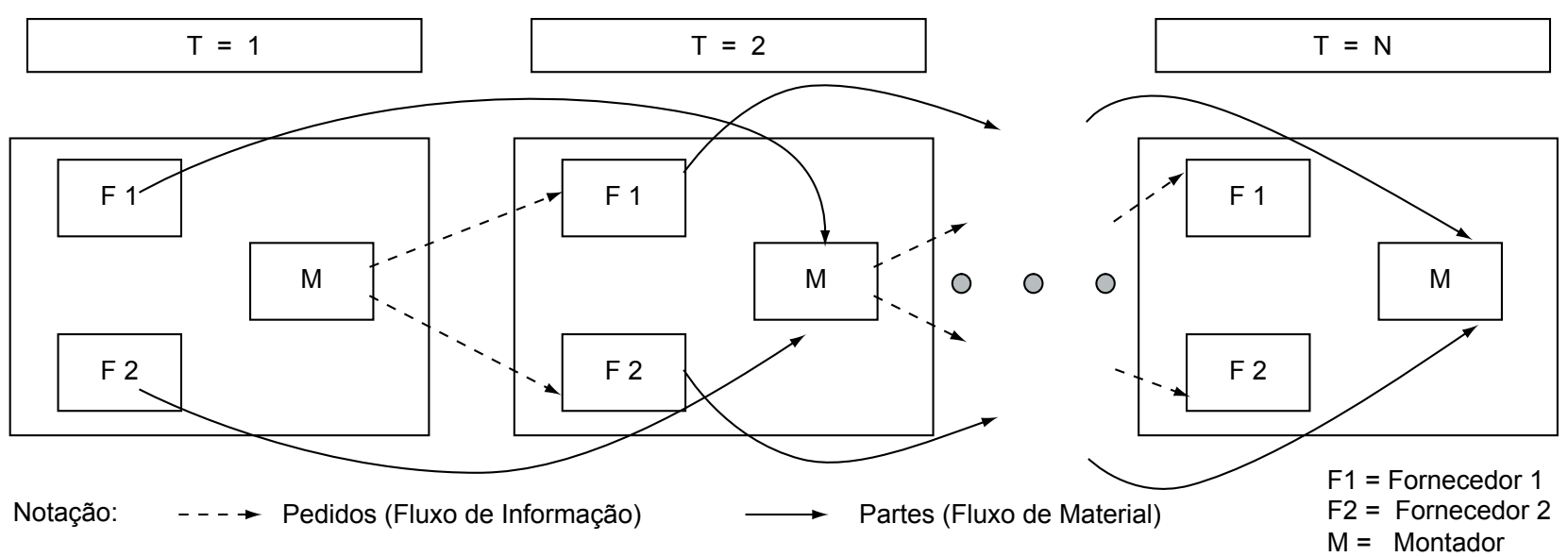

Figura 3. Evolução no tempo de fluxos de pedidos e de material.

material e informação entre empresas ocorrem em intervalo regular de tempo, ou seja, os eventos entre empresas avançam em números inteiros $(1,2,3, \ldots$ horas, dias, etc.). Esta representação constitui grande avanço em relação aos modelos tradicionais, pois permite que a gestão da produção entre empresas possa ser representada por um modelo a tempo discreto, enquanto que as atividades de planejamento e produção, que ocorrem dentro da empresa, podem ser representadas, quando necessário, por eventos discretos.

\section{O ambiente de simulação para CS}

A simulação é constituída por um processo de modelagem e um processo de experimentações sobre este modelo, com o propósito de avaliar o comportamento de um sistema real sob diferentes cenários de operação. Os modelos de simulação são modelos avaliativos, ou seja, avaliam o desempenho de um cenário. A aplicação da simulação a uma CS envolve a modelagem de cada empresa e a representação da relação de negócio entre empresas. Uma forma de realização desta modelagem é pela simulação distribuída.

A proposta para a simulação neste trabalho, para desenvolvimento de um Ambiente para Simulação de Cadeias de Suprimentos (ASCS), considera a independência das empresas, representando-as por um modelo de simulação independente, constituído por (Towill, 1992): demanda percebida por produto (pedidos firmes ou previsão de vendas); um processo de produção ou de agregação de valor na CS; informação sobre o estado corrente das operações; perturbação nas operações e recursos (pessoas, máquinas, matéria-prima); e regras de decisão para processamento e para a priorização de pedidos, planos de produção, gestão do estoque e de materiais (matériaprima e componentes). São regras de negócio entre as empresas, que dependem da forma de cooperação ado- tada e do atraso na transmissão da informação. A experimentação do modelo da CS é feita a partir da integração dos modelos das empresas, pela aplicação das regras de negócio entre empresas, com o suporte de um administrador de rede de simulação e um ambiente de simulação.

\subsection{Administrador de rede de simulação}

Um dos objetivos da simulação distribuída para CS é permitir que cada empresa seja responsável pela construção de seu modelo de simulação, preservando, assim, a sua confidencialidade. Após terminar seu modelo, a empresa deve instalá-lo em um computador, chamado servidor da simulação, aberto a computadores de outras empresas. Este modelo deve ficar em modo de espera, ou seja, estar disponível para interagir com outros modelos de outras empresas, quando houver uma solicitação de simulação. Essa solicitação pode partir de qualquer empresa da CS, autorizada a tal. É considerado que cada empresa participante tenha seu servidor de simulação e que os vários servidores possam comunicar-se entre si formando uma rede, que será chamada rede de simulação. Para controle desta rede, deve haver um administrador da rede com as seguintes funções, Figura 4:

- Autorizar participantes: empresas podem entrar e sair da rede de simulação e controlar o acesso, restringindo-o a determinado computador e a pessoas autorizados;

- Estabelecer a estrutura da CS e a estrutura física da rede de simulação: ao se cadastrar, cada empresa identifica de quem compra, para quem vende e o endereço de rede do computador no qual disponibiliza o modelo e autoriza usuário;

- Manter integridade dos modelos e das simulações: os modelos de simulação não podem ser alterados enquanto estiver rodando uma simulação; e

- Aplicar as regras de negócio: essas regras definem como as empresas trocam material e informação e que tipo de 
informação e calcular medidas para avaliar o desempenho das empresas e da CS.

A atuação do administrador de rede de simulação independe da forma de gestão utilizada pela CS. A responsabilidade do administrador pode ser da empresa que assume a liderança da rede ou uma terceira empresa responsável pelos serviços de "data center". A localização física do administrador de rede de simulação não é importante. $\mathrm{O}$ importante é o acesso seguro às informações administradas. Os servidores de simulação podem estar conectados ao administrador de rede de simulação por diferentes tipos de rede (Extranet, Internet ou Lan), Figura 4, e têm o papel de estruturar a simulação.

\subsection{Ambiente de simulação de cadeias de suprimentos (ASCS)}

$\mathrm{O}$ ambiente ASCS, concebido especialmente para estudos de políticas de gestão em CS (Machado, 2004), representa a dinâmica da simulação a tempo e a eventos discretos e considera dois outros pontos: a lógica de coordenação da simulação e a representação das regras de negócio das empresas e da CS.

\subsubsection{Lógica de coordenação dos mode- los de simulação}

Um dos aspectos fundamentais em simulação é o registro do tempo de ocorrência dos eventos por um relógio de simulação. Esse relógio registra o avanço do tempo da simulação que, pela proposição da seção anterior, ocorre em intervalos discretos. $\mathrm{O}$ modelo da cadeia resulta da interação entre modelos de empresas. Quando um modelo de empresa envia uma mensagem para outro modelo, esta mensagem chega ao destino em um tempo igual ao de origem somado ao tempo de viagem. Ou seja, quando o tempo de viagem é diferente de zero, o relógio do modelo de simulação de destino pode estar à frente do tempo da mensagem recebida. Como o modelo da CS é composto por vários modelos de empresa, há necessidade de coordenar todos os relógios e as estratégias de coordenação podem ser divididas em descentralizada e centralizada.

$\mathrm{Na}$ coordenação descentralizada de simulação, Figura 5a, os modelos de empresa interagem entre si sem que haja um elemento principal com o papel de coordenador dos relógios. Vários autores apresentam propostas para coordenar os relógios de simulação considerando formas de simulação bem genéricas (Lamport, 1978; Ceroni et al., 1999; Seliger et al., 1999; Chen et al., 1999). Por ela, cada empresa recebe as mensagens do período, executa seus processos e envia mensagens e, somente depois de todas essas ocorrências, avança o relógio de simulação.

$\mathrm{Na}$ coordenação centralizada de simulação, Figura $5 b$, existe um elemento central, podendo ser o administrador da rede, que interage constantemente com as simulações dos modelos de empresa, sincronizando o relógio de simulação.

Por este enfoque de coordenação, a sincronização dos relógios de simulação é realizada, unicamente, pelo elemento central, o coordenador da simulação. A cada intervalo de simulação, as mensagens fluem dos modelos das empresas ao coordenador da simulação que, conhecendo a estrutura da rede, controla se todas as mensagens foram recebidas. Usando o exemplo da Figura 3, o coordenador da simulação recebe, em cada período, duas mensagens de fluxo de material com destino a empresa M (Montadora) e recebe duas mensagens de pedidos com origem na empresa $\mathrm{M}$ e destinos em F1 e F2. Essas mensagens são enviadas mesmo que seus valores sejam nulos. O Coor-

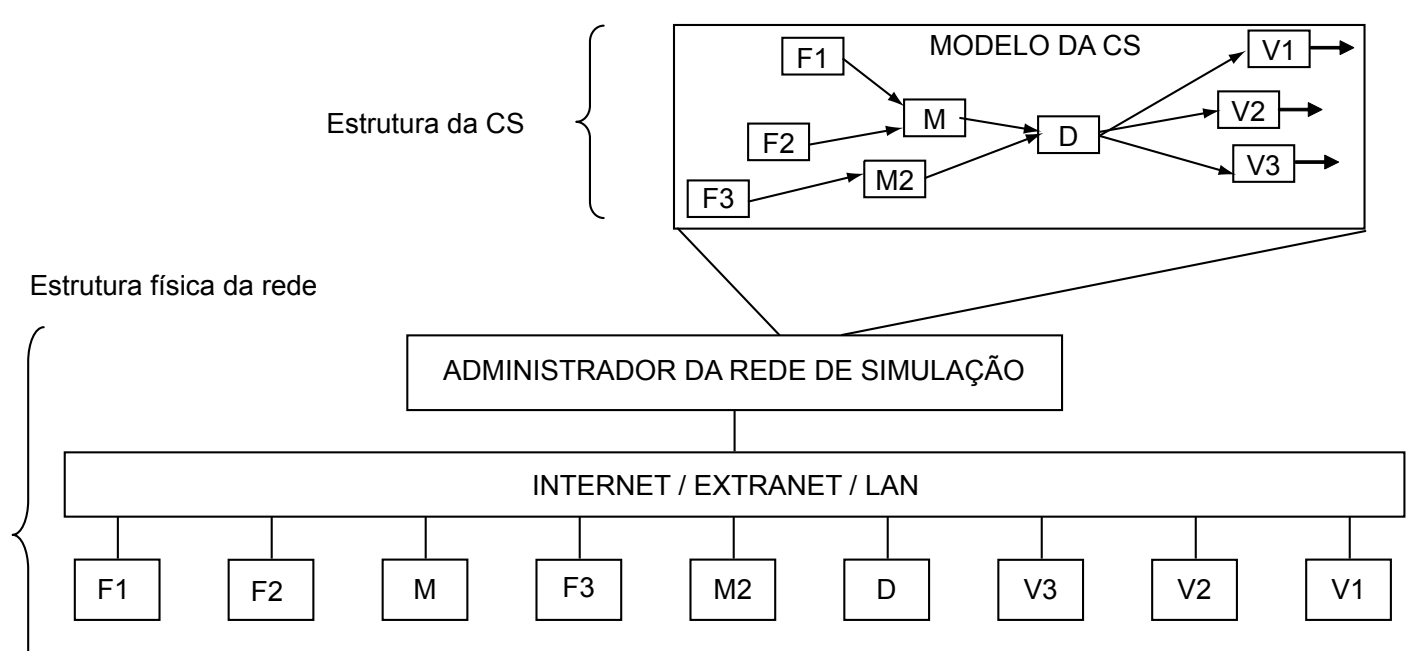

Servidores de simulação: F1, F2, F3 (Fornecedores), M, M2 (Plantas de montagem), D (Distribuidor), V1, V2, V3 (Varejistas)

Figura 4. Administrador de rede de simulação para CS. 
denador, ao final do recebimento de todas as mensagens, aplica as regras adequadas ao nível de negócio entre empresas.

Como as decisões sobre os fluxos de material e informação ocorrem em tempo discreto, as mensagens que saem de uma simulação de empresa podem alcançar as outras simulações no mesmo período ou nos períodos seguintes. No caso, existem duas situações para o coordenador:

O coordenador recebe uma mensagem de simulação de uma empresa, que deve chegar à outra simulação no mesmo período. Neste caso, o coordenador da simulação direciona a mensagem ao seu destino, antes de avançar o relógio das simulações. Na Figura 6a, a empresa M envia, pelo coordenador, um pedido à empresa $\mathrm{F} 1$, que chega no mesmo período de simulação, ou seja, o leadtime do pedido é igual a zero; e

O coordenador recebe uma mensagem de simulação de uma empresa, que deve chegar à outra simulação em $\mathrm{t}$ unidades de tempo. Neste caso, o coordenador da simulação armazena a mensagem e a envia quando o relógio de simulação alcançar o tempo apropriado. Na Figura 6b, por exemplo, a empresa $\mathrm{M}$ envia um pedido à empresa $\mathrm{F} 1$ que chega ao destino com um atraso de " $\mathrm{t}$ " períodos $(\mathrm{t}=1,2, . . \mathrm{N})$, ou seja, o leadtime do pedido é igual a $\mathrm{t}$.

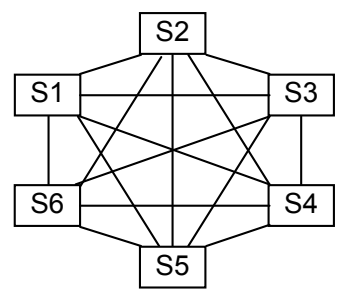

a) Descentralizada

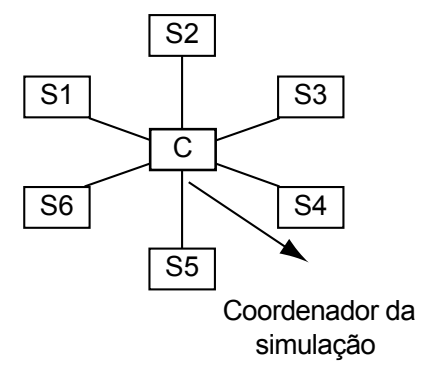

b) Centralizada
No sistema real, o material e a informação fluem separadamente. Assim, existem dois coordenadores para representar este aspecto: um de informação e outro de material. O fluxo de informação flui somente entre as simulações de empresa e o coordenador de informação. O fluxo de material flui entre as simulações de empresa e o coordenador de material. Portanto, ocorrem coordenações separadas para o fluxo de material e o fluxo de informação.

\subsubsection{Simulação de CS em 2 níveis}

A associação das lógicas de coordenação da simulação com os enfoques para gestão resulta nas possibilidades apresentadas na Tabela 1. Em (I), a lógica de simulação é descentralizada e a forma de gestão é descentralizada, podendo ter troca de informação tradicional, compartilhamento total da informação da demanda ou o sistema de informação distribuída. Em (II), a lógica da simulação é centralizada, podendo ser adotada qualquer das três primeiras forma de gestão da Figura 1. Finalmente, em (III), é possível qualquer tipo de compartilhamento de informação e as formas de gestão apresentadas na Figura 1 e Figura 2.

Este artigo assume a lógica de simulação centralizada como o enfoque mais adequado para projeto e planejamento de CS, por possibilitar a experimentação de todas as formas de gestão. Os processos de negócio entre as empresas são representados no nível de coordenação de negócio entre empresas, por um modelo de simulação a tempo discreto.

No segundo nível, nível de empresa, cada empresa pode

Tabela 1. Gestão e lógica de simulação.

Gestão Lógica da Simulação
Descentralizada Centralizada

\begin{tabular}{lll}
\hline Descentralizada & I & II \\
Centralizada & & III \\
\hline
\end{tabular}

Figura 5. Lógicas de coordenação.

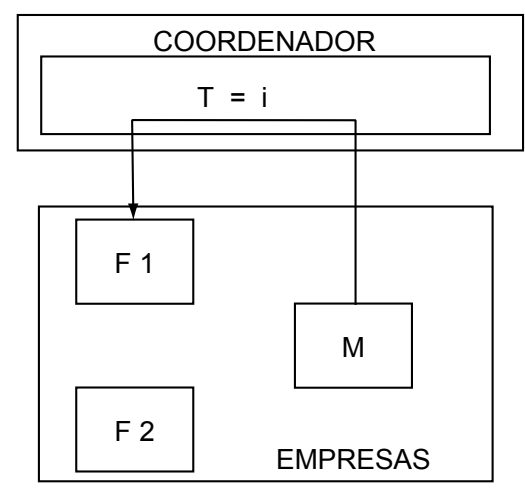

a) Mesmo Período

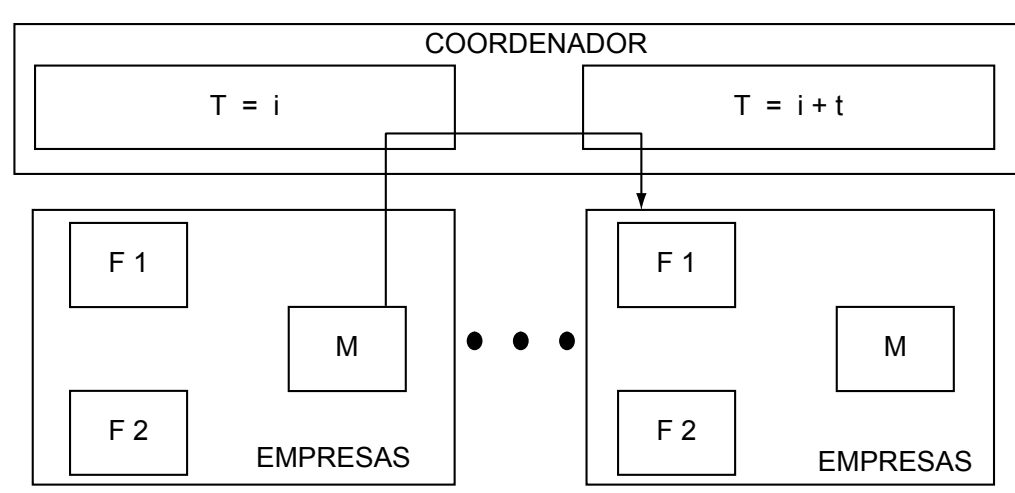

b) Períodos diferentes

Figura 6. Troca de informação. 
ser representada por um modelo a eventos discretos, que é o procedimento comumente utilizado por qualquer software comercial de simulação. Contudo, quando o foco principal está em estudar a dinâmica da CS, o comportamento dos macro-processos de cada empresa pode ser representado por uma regra de negócio que define a forma de processamento de pedido, produção e distribuição ou por funções de probabilidade que gerem uma capacidade produtiva e um tempo de processamento de pedidos.

A integração dos dois níveis ocorre da seguinte forma: cada empresa, atuando como agente autônomo, desenvolve seu modelo e processa sua simulação dentro do intervalo de tempo $[t,(t+1)]$. Ao final deste intervalo, envia a mensagem de seu estado final para o nível de negócio entre as empresas. O coordenador recebe estes dados das empresas parceiras e os processa segundo regras previamente acertadas pelos participantes, estabelecendo metas para o próximo período. Estas metas, a serem cumpridas por cada uma das empresas da cadeia, são o ponto de partida para a simulação da próxima janela de tempo $[(t+1),(t+2))$. Ao final do tempo $(t+2)$, cada empresa alimenta novamente o nível de negócio entre empresas e, assim, sucessivamente. Neste contexto, a simulação do processo de negócio entre empresas ocorre com o relógio da simulação avançando em uma sequiência de valores discretos $(\mathrm{t}=1,2, \ldots \mathrm{T})$.

O nível de coordenação, ao receber as mensagens de todos os outros parceiros, atua como o coordenador do fluxo de material e informação de toda a CS. A coordenação pode ser exercida como uma relação causa efeito ou por ações mais elaboradas, orientadas por regras de negócio, que expressam as formas de cooperação entre as empresas, Figura 7. Várias regras de negócio podem ser implementadas, como será visto na seção de aplicação.

A simulação sugerida é hierárquica e ocorre de forma distribuída. Cada empresa disponibiliza, em seu servidor da simulação, a todos os parceiros, um modelo de simulação para representá-la. Uma das vantagens da estrutura distribuída de simulação é manter o modelo de simulação de cada empresa encapsulado, preservando as informações e as confidencialidades na empresa e enviando somente o comportamento desta, para os diferentes cenários em forma de eventos, para o processo de negócio entre empresas.

Cada empresa tem interesse em disponibilizar o melhor modelo para representar seu processo, pois é este que fará parte de sua relação de negócio com os parceiros. Um modelo adequado aumenta sua confiabilidade e credibilidade junto aos parceiros e abre novas oportunidades de negócio, pois o planejado resultará muito próximo ao realizado.

A implementação da simulação distribuída, com lógica de coordenação centralizada e evolução em tempo discreto, tem, como principal vantagem, permitir uma forma simples de sincronização dos relógios de simulação cuja

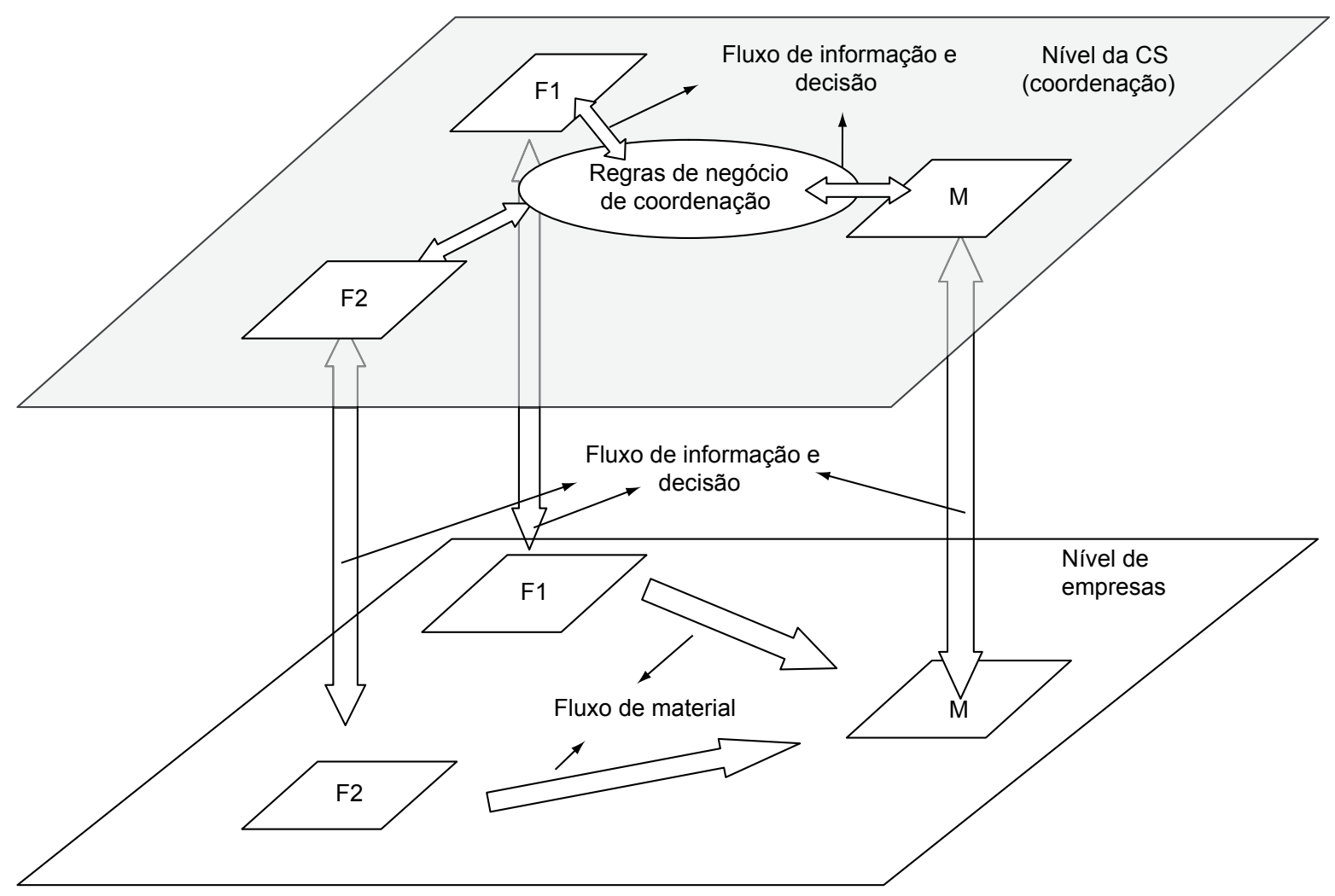

Figura 7. Modelo para cadeia em dois níveis. 
responsabilidade é do coordenador da simulação. Este aguarda o recebimento do fluxo de mensagens de todas as empresas para processar a coordenação. $\mathrm{O}$ aspecto negativo é que a velocidade da simulação será ditada pela conexão mais lenta.

O elemento coordenador da simulação realiza três papéis: coordenador da simulação, coordenador da troca de mensagens com as empresas da CS e ambiente de suporte à decisão. Isto significa que, além de coordenar o fluxo de mensagens entre as empresas, executa as regras de negócio que representam as relações entre as empresas. E por último, este coordenador interage com o usuário que solicitou a simulação. Outras vantagens da adoção de uma coordenação central são: fácil implementação e estrutura de dados simples; a execução da simulação pode ser distribuída; o paralelismo pode ser inteiramente explorado; o esforço de desenvolvimento do modelo é distribuído pelos participantes; as atualizações de modelos locais ficam a cargo de cada empresa, o que possibilita maior fidelidade ao sistema real; a estrutura de simulação se assemelha às estruturas de gestão de planejamento cooperativo; e a confidencialidade dos dados da empresa pode ser preservada.

\subsection{Simulador distribuído para CS}

O Ambiente de Simulação para Cadeias de Suprimentos (ASCS) é um ambiente distribuído, baseado em agentes, especialmente desenvolvido para comparação das diferentes formas de gestão entre empresas. Sua implementação considerou que a simulação distribuída ocorre em tempos discretos e utiliza uma lógica de coordenação centralizada. $\mathrm{O}$ ambiente consiste de dois módulos: modelagem e simulação. O módulo de modelagem permite ao analista definir:

- A configuração da CS formada pelas empresas participantes, bem como o papel de cada uma (varejistas, distribuidores, fábricas e fornecedores);

- As regras de negócio de cada empresa (regras para processo pedido, controle de estoque, gerenciar pedido em atraso, regras de produção, etc.);

- A demanda pode ser definida por funções de distribuição e probabilidade ou obtida de um arquivo externo; e

- Tempos para o fluxo de informação e material, ou seja, o tempo que um pedido leva para chegar ao fornecedor e o tempo que o material leva para chegar ao cliente.

O módulo de simulação cria uma plataforma multiagentes, em que instancia dois agentes de software que coordenam a simulação. $\mathrm{O}$ agente que coordena o fluxo de informação é chamado de Coordenador de simulação. $\mathrm{O}$ agente que coordena o fluxo de material é chamado Coordenador transporte. Cada empresa, representada no modelo de simulação, possui um agente de softwa- re correspondente na simulação. Este agente de software pode ser instanciado em qualquer computador conectado à Internet. Definido o modelo da CS, pela integração de um conjunto de agentes que representa as empresas e por um conjunto de políticas de gestão e controle, passa-se a análise dos aspectos dinâmicos do sistema por simulação a tempo discreto e a evento discreto.

Uma vez que cada entidade de negócio possui um conjunto de habilidades e obrigações, um agente deve possuir um conjunto de atributos e ações, que lhe permita representar o papel da entidade de negócio correspondente. Como exemplo, um agente cliente tem a habilidade de gerar demanda seguindo um padrão estabelecido por uma função de probabilidade ou por um conjunto de dados históricos. Um agente montador tem a habilidade de estabelecer um plano de produção baseado em uma previsão, adquirir componentes, montar seus produtos e entregálos à empresa compradora. Por fim, deve existir uma plataforma que possibilite a comunicação entre os diferentes agentes que representam a CS. Essa comunicação ocorre por meio de mensagens. As mensagens são recebidas pelo agente que as interpreta e ativa a política de controle correspondente. As decisões nas empresas são realizadas nos agentes de empresa, as decisões que envolvem colaboração entre empresas são realizadas pela colaboração dos agentes de empresa, mediados pelo agente de coordenação da simulação. Por exemplo, o agente varejista ao receber pedidos do consumidor:

1. Extrai a informação contida no pedido (tipo do produto, quantidade, tempo de entrega);

2. Verifica se há "no estoque" produtos em quantidade suficiente para atender ao pedido;

3. Se houver, gera uma mensagem, endereçada ao agente do pedido (cliente), confirmando o envio dos produtos. Atualiza o estoque da quantidade enviada; e

4. Se não houver quantidade suficiente, o pedido é registrado como pedido em atraso (backorder). $\mathrm{O}$ atendimento pode ocorrer das seguintes formas: atender ao pedido parcialmente e a parte não atendida é registrada como pedido em atraso. Ou não atender ao pedido, registrando o pedido inteiro como pedido em atraso.

A cada intervalo de simulação é aplicada a política de estoque, que determina o tamanho do pedido a ser enviado em forma de mensagem, ao agente fornecedor.

\subsection{Estrutura do agente}

A descrição do agente contém a especificação de suas habilidades no contexto da CS (Swaminathan et al., 1998). Diferentes habilidades são necessárias para os agentes: cliente, varejista, distribuidor, fábrica/montadora, fornecedor de nível i. Assim, cada agente é especiali- 
zado na atividade que realiza na CS e, portanto, possui características específicas, descritas por um conjunto de vetores de parâmetros, a saber:

- $\mathrm{A}=$ Conjunto de atributos que caracterizam o estado do agente em um dado instante de tempo (posição de estoque, nível de backorder, ordem de produção, produção realizada);

- I = Conjunto de dados que caracterizam o conhecimento que o agente tem de outros agentes e da CS. Por exemplo, este agente tem acesso à informação da demanda no ponto de venda, tem acesso à posição de estoque de empresas clientes e/ou fornecedoras, tem acesso à taxa de ocupação atual da produção dos seus fornecedores;

- $\mathrm{P}=$ Prioridades do agente (em caso de backorder, qual cliente atender primeiro);

- $\mathrm{M}=$ Medidas de desempenho do agente como: média e desvio-padrão do estoque, nível de serviço, giro do estoque, desvio-padrão dos pedidos colocados ao fornecedor;

- $\mathrm{ME}=$ Mensagem de entrada do agente contendo lista de pedidos dos agentes clientes deste agente, lista de material enviada e informação atualizada de outros agentes. O conteúdo dessa informação depende do conjunto I do agente, ou seja, do conhecimento que este agente obtém de outros agentes;

- MS = Mensagem de saída do agente. Após o recebimento da mensagem de entrada e extraindo seu conteúdo, o agente processa os pedidos recebidos, atualiza seu estoque com o material recebido e atualiza o seu conhecimento sobre os outros agentes (I). Em seguida, o agente, por meio de sua política de produção ou estoque, coloca pedidos aos seus fornecedores, envia produtos para os compradores e disponibiliza informação de seu estado para outros agentes. Toda essa informação é encapsulada na mensagem de saída; e

- $\mathrm{PO}=$ conjunto de políticas do agente. Uma política é chamada, quando uma decisão precisa ser feita. A política utiliza a informação contida na (ME), o conhecimento que o agente tem de outros agentes (I), nas prioridades $(\mathrm{P})$ e seu estado atual (A).

\subsection{0 papel dos agentes}

Os agentes de empresa são responsáveis por suprir, manufaturar, montar, estocar produtos e componentes e, o mais importante, atender à demanda. Eles irão definir a estrutura da CS, ou seja, quem participa e o papel de cada participante. Os agentes de empresa são:

- Varejista: O varejista é o responsável em atender à demanda dos clientes. É no varejista que se percebe qual é o nível de serviço no atendimento aos clientes, ou seja, a porcentagem dos pedidos que são atendidos no prazo;
- Distribuidor: A sua responsabilidade é suprir os varejistas. Para isso, o distribuidor solicita produtos à fábrica e os armazena esperando atender aos pedidos dos varejistas;

- Fábrica: A fábrica representa as operações nas quais os produtos são manufaturados. A fábrica pode atender o distribuidor ou os varejistas diretamente, isso depende da modelagem da CS. A fábrica pode trabalhar de duas formas: empurrando a produção ou puxando a produção;

- Fornecedores: Os fornecedores são responsáveis pelo suprimento da matéria-prima e componentes da fábrica. Um fornecedor pode suprir outro fornecedor e assim por diante; e

- Cliente: Os clientes definem o comportamento da demanda nos pontos de venda como volume de pedidos, sua variação e sazonalidade;

- Além dos agentes de empresa que representam a CS, há um agente responsável pela coordenação e um agente responsável pelo transporte:

- Agente Coordenador da simulação: é responsável pela administração da simulação. Este agente prepara a simulação interagindo com os outros agentes, coordena e sincroniza a simulação pelo controle do fluxo de mensagens entre os agentes, executa políticas de gestão da CS e disponibiliza os resultados após a simulação; e

- Agente Coordenador do transporte: este agente controla as mensagens que representam o fluxo de material. Ele permite simular o tempo de transporte, atrasos, capacidades, frequiência dos embarques e desembarques de material.

\subsection{0 fluxo de mensagens}

As mensagens durante a simulação representam dois tipos de fluxos:

- Fluxo de material: mensagens que estão relacionadas à entrega de componentes e produtos de um agente a outro. Quando esta mensagem chega ao agente destino, atualiza o seu estoque. Todo o fluxo de material passa por um agente especial chamado agente transporte, que tem por objetivo sincronizar o fluxo de material e simular alguns aspectos do transporte, como o tempo de atraso do sistema;

- Fluxo de informação: mensagens que representam o fluxo de informação entre agentes. Entre elas estão: pedidos de produtos aos fornecedores, informação da taxa de ocupação, previsão de demanda, informação do nível de estoque, planejamento da produção, etc.

\subsection{Políticas de gestão das empresas}

Para que diferentes formas de gestão da CS possam ser modeladas, é necessário que o modelo considere não 
somente a configuração da CS, mas as políticas adotadas pelas empresas e pela CS. Essas políticas são incorporadas nos agentes do modelo de simulação. $\mathrm{O}$ ambiente apresentado aqui modela as seguintes políticas:

- Política de demanda: É agregada aos agentes clientes somente. Esta política define o comportamento da demanda (volume da demanda, sua variação e sazonalidade);

- Política de estoque: Está em todos os elementos da cadeia exceto os agentes clientes. Sua função é controlar o nível de estoque, para um dado nível de atendimento do cliente, e estabelecer pedidos aos fornecedores. As principais regras utilizadas nesta política são: $(\mathrm{s}, \mathrm{S}), \mathrm{s}$ atualizado, (s,Q), s atualizado com informação da demanda;

- Política de compra: Estabelece como um agente adquire matéria-prima ou produtos. Caso haja mais de um fornecedor, estabelece-se uma regra para suprimento que pode envolver contrato, observar taxa de ocupação do fornecedor ou seu nível de serviço;

- Política de processamento do pedido: Define como os agentes priorizam os pedidos. A prioridade pode ser por produtos ou clientes. No caso de ocorrer backorder, define produtos e clientes prioritários e se haverá atendimento parcial ou total;

- Política de produção: Define como a fábrica irá produzir. As duas formas principais são: o sistema empurra, baseado em uma previsão de demanda que também deve ser definida, ou sistema puxa, em que a produção é disparada contra pedidos. A capacidade de produção deve ser definida, entretanto, as características do chão de fábrica não são modeladas em detalhe; $\mathrm{e}$

- Política de transporte: Define as características da movimentação do material e é implementada no agente de transporte. As principais características são: tempo de transporte, variação desse tempo e capacidade.

\section{Aplicação}

Esta seção analisa uma CS composta de: Varejista, Distribuidor, Fábrica e Fornecedor, Figura 8. Este sistema, embora simples, é adequado para a análise do comportamento de empresas parceiras em um negócio, uma vez que permite o analista se concentrar nos parâmetros e índices de cada estágio de produção, sem se preocupar com a complexidade do modelo físico. A complexidade pode existir de maneira implícita, uma vez que o "Agente Cliente" pode ser resultado de uma combinação de clientes individuais, o mesmo podendo ocorrer com o "Agente Fornecedor". Neste estudo, a demanda do cliente é gerada segundo comportamento sazonal definido pela Figura 9 e são analisados três cenários de gestão:

- Cenário 1: Troca de informação tradicional;

- Cenário 2: Compartilhamento da informação de demanda; e

- Cenário 3: Decisão de produção e distribuição centralizada na Fábrica.

A capacidade do sistema produtivo (fornecedores e fábricas) é considerada infinita, embora não haja dificuldades em limitá-la. No ASCS, o último elemento de qualquer ramo da CS é um F_EXTERNO de capacidade ilimitada, ou seja, capaz de atender a qualquer pedido.

Os índices de desempenho considerados para comparação das três alternativas de cenário são:

- Nível de serviço;

- Estoque médio; e

- Razão dos desvios-padrão dos pedidos das empresas consecutivas.

O nível de serviço é o percentual dos itens (que foram pedidos) entregues no prazo. Entretanto, este indicador isolado não indica eficiência de uma empresa, uma vez que altos estoques podem contribuir para melhoria deste índice, contudo resultando em alto custo . O estoque

\section{程 Ambiente de modelagem e simulação de Cadeias de Suprimento}

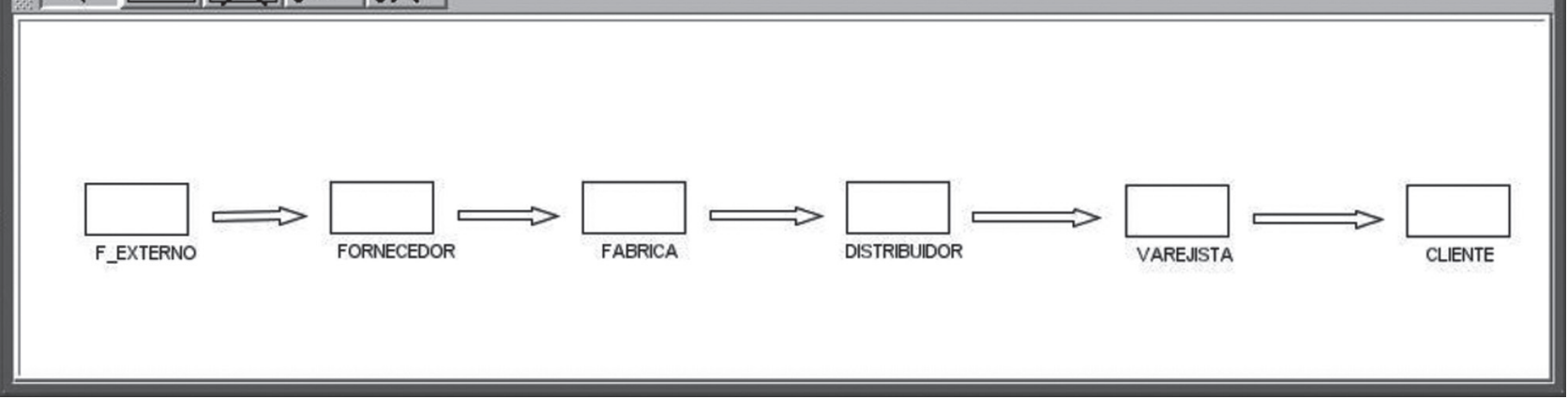




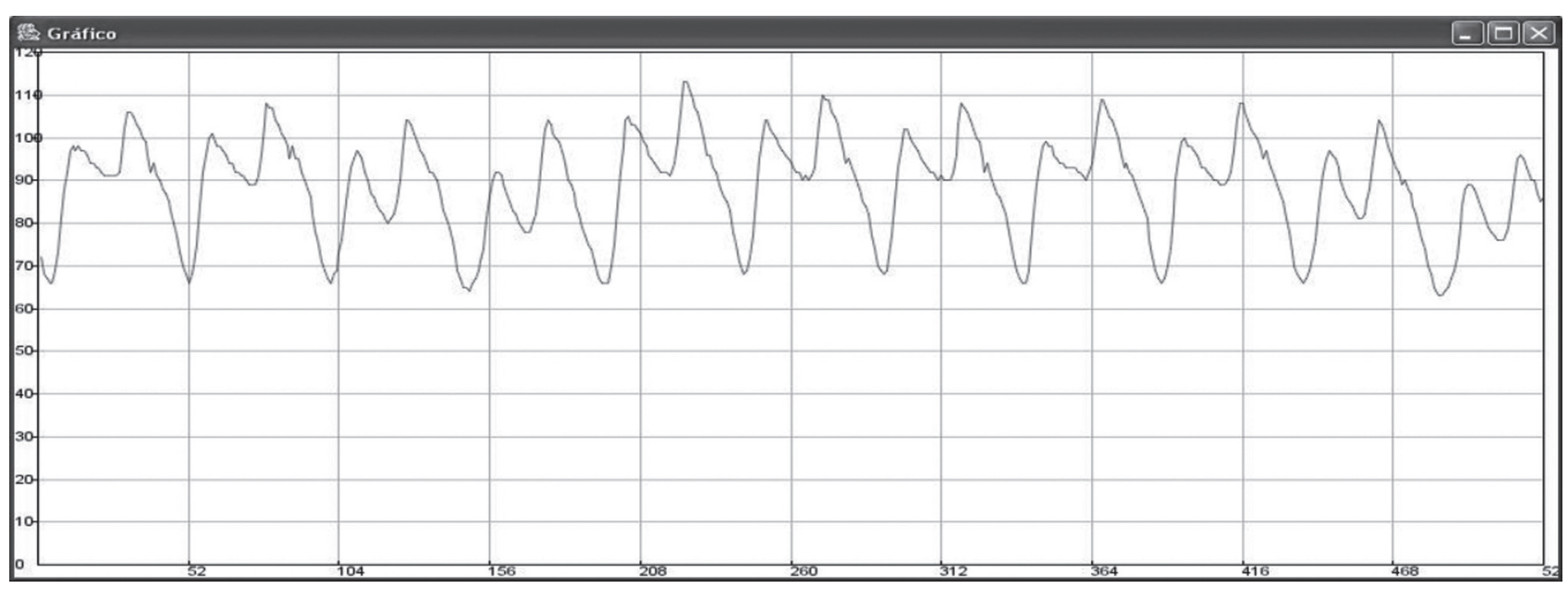

Figura 9. Demanda utilizada nas simulações.

médio é outro indicador importante que, analisado juntamente com o nível de serviço, pode indicar o desempenho de uma empresa. A razão entre os desvios-padrão dos pedidos de empresas consecutivas indica a taxa de crescimento da variação dos pedidos, o que representa uma forma de medir o efeito Chicote (Chen et al., 2000).

A política de estoque adotada para todas as empresas na simulação é a política S com atualização periódica (SimchiLevi, 2000). A cada período, as empresas colocam pedidos aos seus fornecedores para elevar seus estoques ao nível $\mathrm{S}$, que é atualizado periodicamente, baseado no histórico da demanda ou em alguma previsão. Duas formas de previsão são utilizadas nos experimentos: a média móvel e a suavização exponencial. Na média móvel, a média $\left(\mu_{t}\right)$ e o desvio-padrão $\left(\sigma_{t}\right)$ no período t são baseados nos "n" últimos pedidos $\left(\mathbf{p}_{\mathbf{i}}\right)$ :

$$
\mu_{\mathrm{t}}=\frac{\sum_{\mathrm{i}=\mathrm{t}-\mathrm{n}+1}^{\mathrm{t}} \mathrm{p}_{\mathrm{i}}}{\mathrm{n}} \sigma_{t}^{2}=\frac{\sum_{\mathrm{i}=\mathrm{t}-\mathrm{n}+1}^{\mathrm{t}}\left(\mathrm{p}_{\mathrm{i}}-\mu_{t}\right)^{2}}{\mathrm{n}-1}
$$

E o nível S de estoque é calculado como

$$
\mathrm{S}=\mathrm{L} \mu_{\mathrm{t}}+\sigma_{\mathrm{t}} \sqrt{\mathrm{L}} \mathrm{z}
$$

em que, L é o tempo de atraso da reposição (soma do tempo de atraso do fluxo de pedido com o tempo de atraso do fluxo de material). A componente $L \mu_{t}$ corresponde ao estoque necessário para atender uma demanda por $\mathrm{L}$ períodos de simulação até a chegada do pedido. Como a demanda é aleatória, faz-se necessário um estoque de segurança, calculado pela segunda componente utilizando o desviopadrão do período $t\left(\sigma_{t}\right)$ e o fator $z$, relacionado ao nível de serviço (Por exemplo, $\mathrm{z}=1,88$ corresponde a $98 \%$ de atendimento).

$\mathrm{Na}$ suavização exponencial, calcula-se uma previsão a cada período, utilizando a seguinte expressão:

$$
\overline{\mathrm{p}}_{\mathrm{t}+1}=\mathrm{f} \mathrm{p}_{\mathrm{t}}+(1-\mathrm{f}) \overline{\mathrm{p}}_{\mathrm{t}} \quad 0 \leq \mathrm{f} \leq 1
$$

O parâmetro f é conhecido como constante de suavização. Quanto mais f se aproxima de 1, maior será o peso das observações mais recentes. O nível $\mathrm{S}$ é obtido pela seguinte expressão:

$$
S=L \bar{p}_{n+1}+\text { estoque de segurança }
$$

A componente $L \bar{p}_{n+1}$ corresponde ao estoque neces-

sário para atender uma demanda por L períodos de simulação até a chegada do pedido. A segunda componente corresponde ao estoque de segurança. A seguir os cenários de simulação serão descritos.

\subsection{Cenário 1: Troca tradicional de infor- mação}

As características do modelo são apresentadas na Tabela 2. O atraso no fluxo de informação é o tempo entre a saída de um pedido de uma empresa e o tempo de chegada em outra empresa. $\mathrm{O}$ atraso no fluxo de material é o tempo entre a saída dos produtos de uma empresa e o recebimento pela outra empresa. Neste experimento, não há atraso no fluxo de informação e o atraso no fluxo de material é de 2 períodos de simulação. A demanda, gerada externamente, apresenta dois picos que se repetem em intervalos de, aproximadamente, 50 períodos, Figura 9. A demanda média é de 90,1 e seu desvio-padrão é de 11,6.

Todos os experimentos desta seção utilizam essa demanda, abrangendo 520 períodos de simulação com 100 períodos de aquecimento, como mostrado na Tabela 2. Isto significa que os 100 primeiros períodos de simulação são usados para que o sistema entre em um estado de equilíbrio e para que as condições iniciais não interfiram nos resultados. Os resultados estão na Tabela 3. A Figura 10a mostra os níveis de estoque e a Figura 10b mostra os pedidos das empresas respectivamente.

\subsection{Cenário 2: Compartilhamento total da demanda}

Neste cenário, a informação da demanda é passada a todos os participantes da CS em tempo real. Cada em- 
Tabela 2. Parâmetros do modelo e da simulação.

Demanda

Atraso no fluxo de informação

Atraso no fluxo de material

Política de estoque adotada pelos elementos da CS

Política de produção

Número de períodos de aquecimento

Número de períodos por simulação

\section{Sazonal}

Nenhum

2 períodos

Média móvel (10 períodos, $\mathrm{z}=1,88$ )

Produz para estoque (Make-to-Stock) sem restrição de capacidade 50

520

Tabela 3. Resultados das simulações dos 3 cenários.

\begin{tabular}{lcccc}
\hline \multicolumn{4}{c}{ Cenário 1: Troca tradicional de informação } \\
\hline \multicolumn{3}{c}{ Empresas } & Estoque & \multicolumn{2}{c}{ Pedidos } \\
& Média & Nível de Serviço & Desvio-padrão & Acréscimo no D.P. \\
\hline Varejista & 109,5 & $87,2 \%$ & 15,1 & - \\
Distribuidor & 119,5 & $90,8 \%$ & 21,0 & $39 \%$ \\
Fábrica & 118,3 & $97,0 \%$ & 37,6 & $38 \%$ \\
Fornecedor & 158,8 & $35,8 \%$ & 57,2 & $52 \%$ \\
\hline
\end{tabular}

\section{Cenário 2: Compartilhamento da informação da demanda}

Empresas

\begin{tabular}{lcccc} 
& Média & Nível de Serviço & Desvio-padrão & Acréscimo no D.P. \\
\hline Varejista & 99,3 & $90,9 \%$ & 14,0 & - \\
Distribuidor & 103,1 & $91,6 \%$ & 18,6 & $33 \%$ \\
Fábrica & 100,4 & $96,7 \%$ & 27,8 & $49 \%$ \\
Fornecedor & 106,6 & $60,2 \%$ & 39,4 & $42 \%$ \\
\hline
\end{tabular}

\section{Cenário 3: Centralização na Fábrica}

Empresas

Estoque

\begin{tabular}{rccc} 
Média & Nível de Serviço & Desvio-padrão & Acréscimo no D.P. \\
\hline 121,0 & $91,7 \%$ & 14,0 & - \\
89,9 & - & - & - \\
114,4 & $100,0 \%$ & 19,7 & - \\
104,6 & $78,3 \%$ & 26,5 & $35 \%$ \\
\hline
\end{tabular}

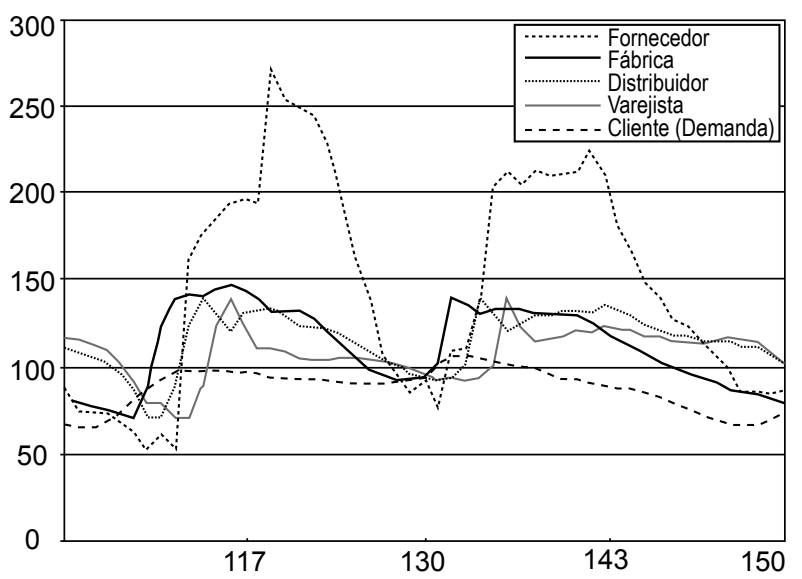

(a) Cenário 1 - Estoque

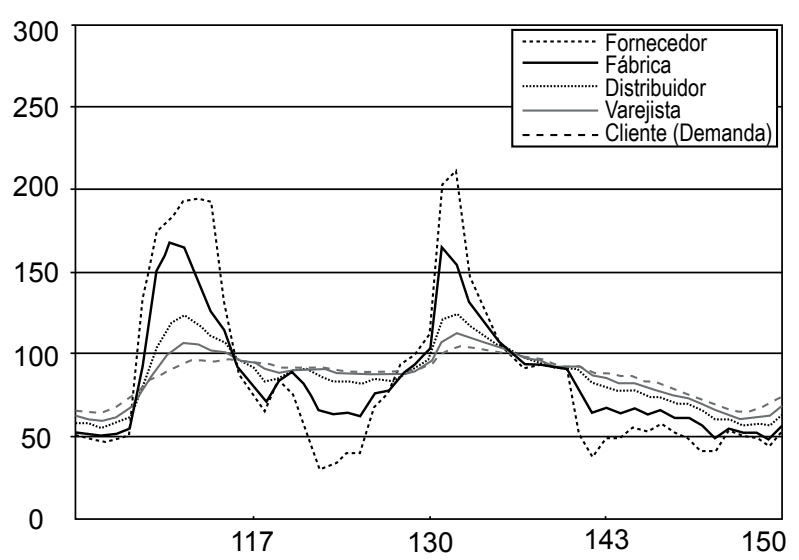

(b) Cenário 1 - Pedidos

Figura 10. Gráficos dos estoques e pedidos para o Cenário 1. 
presa calcula o valor $\mathrm{S}$ considerando a média ponderada entre o pedido do cliente imediato e a informação da demanda (cliente final). No Varejista, o pedido é a própria demanda. As regras para este cenário foram configuradas da seguinte forma:

- Varejista - utiliza suavização exponencial baseada na demanda (constante de suavização $=0,9$ ); $\mathrm{e}$

- Demais empresas - utilizam 50\% média móvel (Perío$\operatorname{dos}=4, z=1,88$ ) baseada na demanda e $50 \%$ suavização exponencial (constante de suavização $=0,8$ ).

Os resultados deste cenário estão na Tabela 3. As Figuras 11 a e 11b mostram os níveis de estoque e pedidos das empresas respectivamente.

\subsection{Cenário 3: Decisão de produção e dis- tribuição centralizadas na fábrica}

Neste cenário, a Fábrica, baseada nas informações de demanda, assume a gestão da CS e estabelece o ritmo de produção, visando suprir as empresas a jusante (Distri-

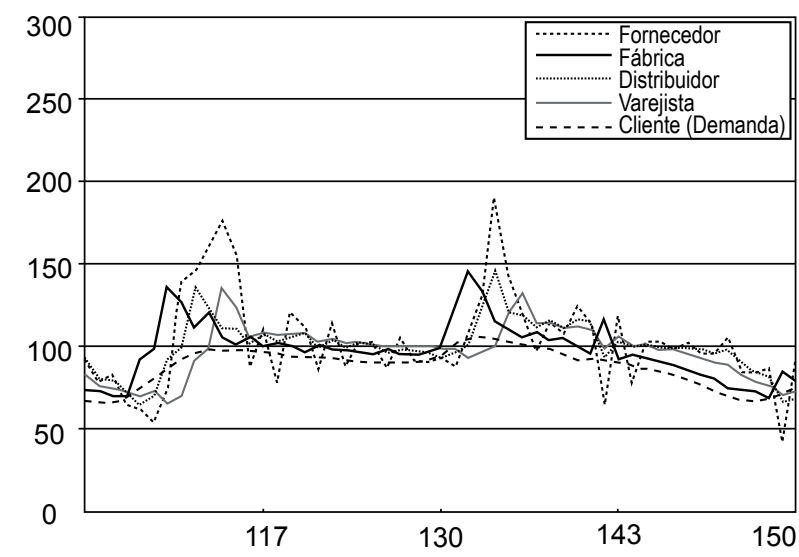

(a) Cenário 2 - Estoque buidor e Varejista), que terão seus pedidos e seus estoques gerenciados pela fábrica (Disney e Towill, 2003). Os resultados estão na Tabela 3. Os gráficos 12a e 12b mostram os níveis de estoque e pedidos das empresas respectivamente.

\subsection{Análise dos resultados}

A seguir, os resultados dos três cenários serão analisados e comparados quanto ao desempenho segundo os três indicadores acima estabelecidos.

Cenário 1: os níveis de serviço das 4 empresas estão abaixo da meta da política de estoque (98\%). Isto ocorre porque a deficiência no suprimento do fornecedor influi na queda do nível de serviço da empresa compradora. Ou seja, o atraso na entrega de uma empresa influi para que a empresa a jusante também tenha problemas de entrega no prazo. Essa influência se soma no sentido jusante da CS. Os desvios-padrão dos pedidos e os estoques médios das empresas crescem na direção montante da CS. O primeiro aspecto evidencia o efeito Chicote. $\mathrm{O}$ segundo aspecto

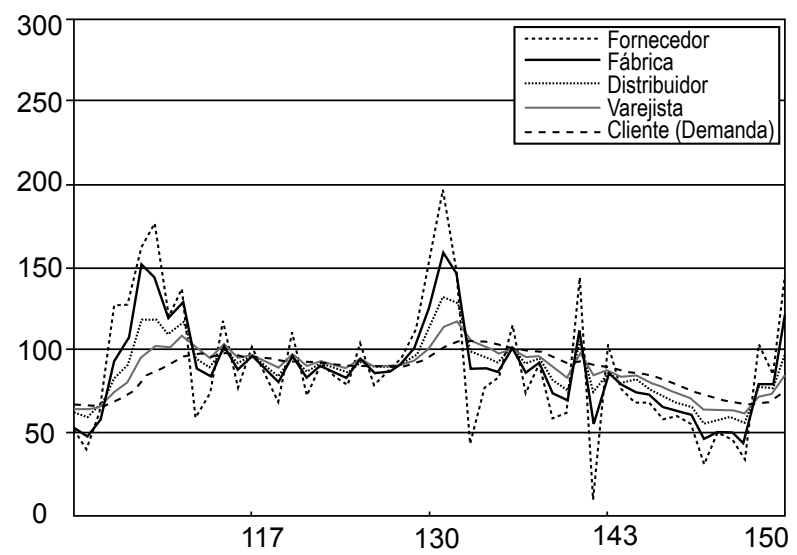

(b) Cenário 2 - Pedidos

Figura 11. Gráficos dos estoques e pedidos para o Cenário 2.

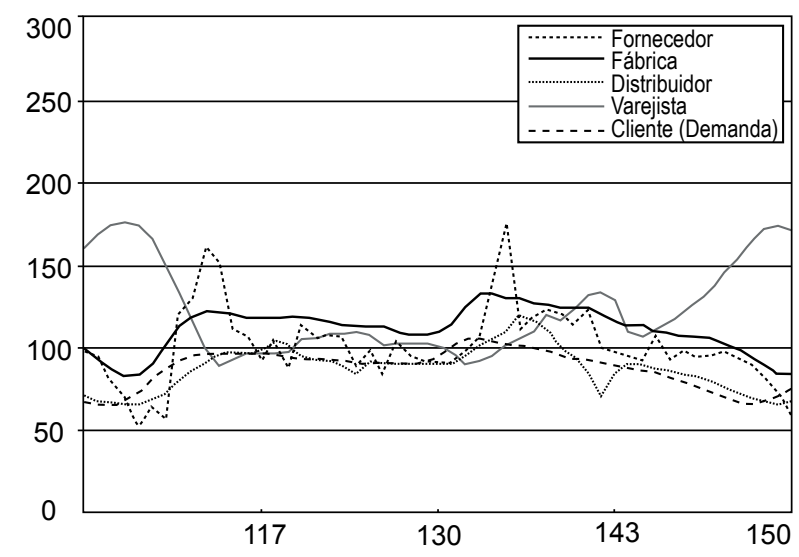

(a) Cenário 3 - Estoque

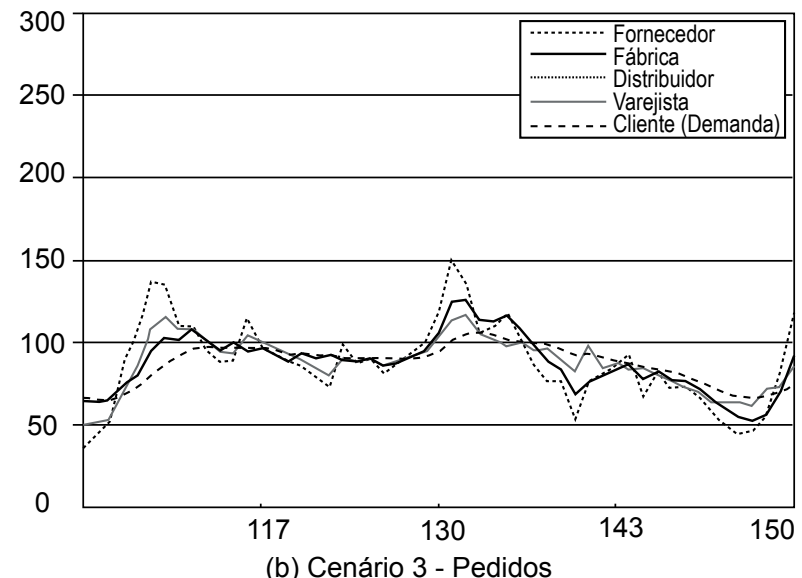

(b) Cenário 3 - Pedidos

Figura 12. Gráficos dos estoques e pedidos para o Cenário 3. 
é conseqüência do primeiro, porque com a maior variação dos pedidos, maior deve ser o estoque de segurança para atendê-los. A Figura 10a mostra a elevação dos estoques e sua crescente oscilação no sentido montante. A Figura 10b mostra como as oscilações de demanda são amplificas nos pedidos. Pode ser verificado que há uma queda mais acentuada no nível de serviço entre a Fábrica e o Fornecedor. Isso ocorre porque há 2 estoques para gerir e um leadtime maior. Dois estoques, porque há o estoque de produtos acabados e o estoque de matéria-prima que supre a produção. O leadtime é maior, porque somase o leadtime de reposição mais o leadtime de produção.

Cenário 2: melhorou o nível de serviço de três empresas. Na Fábrica, ficou praticamente estável. Os níveis dos estoques diminuíram mais de $10 \%$ no Varejista e no Distribuidor, quase $20 \%$ na Fábrica e quase $30 \%$ no Fornecedor. Houve melhora não acentuada no efeito Chicote, uma vez que todos os desvios-padrão dos pedidos deste cenário são menores que o do Cenário 1. Neste caso, a média móvel considera apenas 4 períodos para base de cálculo. Isto provocaria mais oscilações na média móvel e no desvio-padrão em relação ao cenário anterior, anulando a suavização que o compartilhamento da informação proporciona. Entretanto, a média móvel ficou mais ágil para acompanhar a sazonalidade da demanda, influenciando, positivamente, nos níveis de serviço e estoques, principalmente entre Fornecedor e Fábrica. A forte oscilação provocada pela regra de previsão utilizada neste cenário pode ser visualizada nas Figuras 11a e 11b. Pode ser visto também que as curvas se aderem melhor à curva da demanda, o que mostra maior agilidade da regra de previsão.

Cenário 3: A Fábrica, tendo acesso à informação da demanda, percebe a sazonalidade e aumenta ou diminui a produção para sincronizar-se às necessidades do consumidor. A maior visibilidade da demanda permite que as oscilações, tanto do estoque quanto do pedido, sejam baixas na Fábrica e no Fornecedor. Como a variação é menor, os estoques de segurança podem ser menores, o que leva a um estoque médio menor. Como esta política de gestão suaviza as oscilações na produção da Fábrica, este comportamento é transmitido ao Distribuidor. O Varejista assume a variação da demanda, apresentando maior estoque médio e desvio-padrão. Este enfoque de gestão privilegia os níveis de serviços, principalmente no Varejista, além de gerar um estoque total, no sistema, menor que nos casos anteriores. A Figura $12 \mathrm{~b}$ mostra como os pedidos da Fábrica e do Fornecedor acompanham melhor as oscilações da demanda.

\section{Conclusões}

O desempenho de uma Cadeia de Suprimentos é grandemente influenciado pelas políticas de gestão e quanto maior for a cooperação entre os parceiros, maiores vantagens resultarão para as empresas individuais e para a competitividade da cadeia. Neste sentido o compartilhamento da informação aumenta a visibilidade de todos os elementos da CS sobre comportamentos futuros do consumidor e possibilita que cada empresa se prepare para atender possíveis variações com maior nível de serviço. Isto pode ser verificado na comparação entre os três cenários simulados neste trabalho.

Um aspecto interessante é a forma de combinar regras de previsão de demanda para cada empresa da CS. Quando uma regra de previsão de demanda é ágil, ou seja, responde rapidamente às mudanças no padrão da demanda, essa regra tende a ser muito oscilante, prejudicando a gestão do estoque da produção. Entretanto, essas regras podem ser ajustadas para trabalhar com maior suavidade beneficiando a gestão de estoque e da produção. Mas, essa configuração tende a ser mais lenta quanto à mudança no padrão da demanda. Desta forma, é interessante combinar as regras de previsão de forma diferente de acordo com a posição da empresa na CS. No Varejista, a regra deve ser ágil, mesmo que provoque mais oscilações. Na Fábrica, a regra deve ser mais suave para não prejudicar a gestão da produção, com mudanças constantes. Havendo o compartilhamento da informação da demanda, a Fábrica pode antecipar as oscilações de demanda e isso compensa a menor agilidade da regra de previsão que privilegia a suavidade.

\section{Referências Bibliográficas}

AENZEN, B.; SHUMWAY, H. Driven by Demand: A Case Study. Supply Chain Management Review, New York, p. 12-23, Jan.-Feb., 2002. Disponível em: <http://www. manufacturing.net/scm/index.asp? layout=articleWebzin e\&articleid=CA197691>. Acesso: em 5 Janeiro 2004.

AZEVEDO, A.; SOUSA, J. P. Agile Supply Chain Management: Challenges, Requirements and Solutions. In: CONFERENCE ON MANAGEMENT AND CONTROL OF PRODUCTION AND LOGISTICS, 2, 2000, Grenoble,
França. Proceedings of MCPL'2000. Oxford, UK:Editora Elsevier Science Ltd, 2000. p.1-6.

CARVALHO, M. F.; CAMPOS, R. A hierarchy for cooperative management and control of production and logistics. In: CONFERENCE ON MANAGEMENT AND CONTROL OF PRODUCTION AND LOGISTICS, 1, 1997, Campinas, Brasil. Proceedings of MCPL'97. Oxford, UK: Elsevier Science Ltd, 1997. p. 420-425.

CERONI, J. A.; MATSUI, M.; NOF, S. Y. Communication- 
based coordination modeling in distributed manufacturing systems. International Journal of Production Economics, London, UK, v. 60-61, p. 281-287, 1999.

CHEN, H. B. et al. eSCA: A thin-client/server/web-enabled system for distributed supply chain simulation. In: WINTER SIMULATION CONFERENCE, 1999, Phoenix, USA, Proceedings of WSC'99. Evanston/Chigago, USA: Institute for Operations Research and the Management Sciences, p. 1371-1377, 1999.

CHEN, F. et al. Quantifying the bullwhip effect in a simple supply chain: the impact of forecasting, lead-times and information. Management Science, Evanston/Chigago, USA, v. 46, n. 3, p. 436-443, 2000.

DISNEY, S. M.; TOWILL, D. R. Vendor-managed inventory and Bullwhip reduction in a two-level supply chain. International Journal of Operations and Production Management, Bradford, UK, v. 23, n. 6, p. 625-651, 2003.

FORRESTER, J. W. Industrial dynamics. 1. ed. Boston: MIT Press, 1961. 479 p.

FREDRIKSSON P. Modular assembly in the car industry - an analysis of organizational forms influence on performance. European Journal of Purchasing \& Supply Management. London, UK, v. 8, p. 221-233, 2002.

FURTADO, P. G.; CARVALHO, M. F. Optimization Structures for Supply Chain Management. In: WORKING CONFERENCE ON INFRASTRUCTURES FOR VIRTUAL ENTERPRISES, 3., 2002, Sesimbra, Portugal. Collaborative Business Ecosystems and Virtual Enterprises. Norwell, USA: Kluwer Academic Publishers, 2002. p. 227-236.

KELLERT, P.; TCHERNEV, N.; FORCE, C. Object Oriented Methodology for FMS modelling and simulation. International Journal of Computer Integrated Manufacturing. New York, s. 1., v. 10, n. 6, p. 405-434, 1997.

LAMPORT, L. Time, clocks, and the ordering of events in a distributed system. Communications of the ACM, New York, v. 21, n. 7, 1978.

LEE, H. L.; BILLINGTON, C. Material Management in Decentralized Supply Chains. Journal of the Operation Research, Hampshire, England, v. 41, n. 5, p. 835-847, 1993.

LEE, H. L.; PADMANABHAN, V.; WHANG, S. Information distortion in a supply chain: the bullwhip effect. Management Science. Chicago, USA, v. 43, p. 546-558, 1997.

LEE, H.; WHANG, S. Descentralized Multi-echelon Supply Chains: Incentives and information. Managemente Science. Chicago, USA, v. 45, n. 5, p. 633-640, 1999.

LEE, H. L.; WHANG S. E-Business and Supply Chain Integration. Stanford Global Supply Chain Management Forum, Stanford, 2001. Disponível em: <http://www. stanford.edu/group/scforum/Welcome/White\%20Papers/
EB_SCI.pdf $>$. Acesso: em 29 Agosto 2002.

MARCA, D. A.; MCGOWAN, C. L. SADT: Structured Analysis and Design Technique. 1. ed. New York: McGraw-Hill, 1988. 392 p.

MACHADO, C. Desenvolvimento de um sistema de simulação para Cadeias de Suprimentos. 2004. 125f. Tese (Doutorado em Engenharia Mecânica) - Faculdade de Engenharia Mecânica, Universidade Estadual de Campinas, Campinas, 2004.

OLIVER, K.; CHUNG,A.; SAMANICH, N. Beyond Utopia: The Realist's Guide to Internet-Enabled Chain Management. Strategy+business, 2001. Disponível em: <http:// www.strategy-business.com/press/enewsarticle/22165>. Acesso em: 3 maio 2003.

SELIGER, G. et al. On the HLA- and Internet-based coupling of commercial simulation tools for production networks. 1999 International Conference On Web-Based Modeling And Simulation, San Diego, 1999. Disponível em: < http://www.cs.uni-magdeburg.de/ strassbu/publications/websim99/websim99.html>. Acesso: em 10 novembro 2001.

SIMCHI-LEVI, D.; KAMINSKY, P.; SIMCHI-LEVI,E. Designing and Managing the Supply Chain - concepts, strategies, and case studies. 1. ed. New York: McGrawHill, 2000. 384 p.

SRINIVASAN, K.; JAYARAMAN, S. The changing role of information technology in manufacturing. Computers in Industry. London, UK, s. 1, v. 32, n. 3, p. 42-48, 1999.

STEVENS. G. Integrating the Supply Chain. International Journal of Physical Distribution and Material Management, West Yorkshire, England, n. 8, p. 3-8, 1989.

SWAMINATHAN, J. M.; SMITH, S. F.; SADEH, N. M. Modeling Supply Chain Dynamics: A Multiagent Approach. Decision Sciences. Atlanta, USA, v. 29, n. 3, p. 607632, 1998.

TOWILL, D. R.; NAIN, M. M.; WIKNER, N. J. Industrial Dynamics Simulation Models in the design of Supply Chain. International Journal of Physical Distribution \& Logistics Management, West Yorkshire, England, v. 22, n. 5, p. 3-13, 1992.

VERNADAT, F. Requirements for Simulation Tools in Enterprise Engineering. In: CAR\&FOF'99, 15., 1999, Campinas. Proceedings of the 15th International Conference on CAD/CAM, Robotics and Factories of the Future. Águas de Lindóia, SP, v. 1, p. 19-24, 1999.

WESTON, R. H.; GILDERS, P. J. Enterprise engineering methods and tools which facilitate simulation, emulation and enactment via formal models. In: BERNUS, P.; NEMES, L. Modelling and Methodologies for Enterprise Integration. 1. ed. London, UK: Chapman \& Hall, 1996, p. 1-16. 


\section{ANALYSIS OF SUPPLY CHAIN MANAGEMENT POLICIES THROUGH SIMULATION MODELS}

\section{Abstract}

The comparison of different approaches for information sharing and management is relevant in the design and operation of supply chains. This comparison allows one to identify gains in service level and to estimate costs as a result of increased information exchange or increased inventory levels. This article discusses distributed and centralized management approaches and defines a distributed simulation environment designed specifically to represent supply chains, whose main advantage is the discrete time evolution of the simulation. An application is used to demonstrate the environment's resources and to evaluate the gains obtained through different information distribution and management policies.

Keywords: supply chain, distributed simulation, management policies, cooperative enterprise, business management. 